\title{
Teaching Reform of Precision Agriculture Technology Based on Virtual Reality
}

\author{
Ying Liu ${ }^{1}$, Gangshun $\mathrm{Rao}^{1}$, Jianping $\mathrm{Chen}^{2}$, Hanqiao $\mathrm{Hu}^{1}$, Yuduan $\mathrm{Ou}^{1}$ and \\ Yingbin $\mathrm{Xue}^{3, *}$ \\ ${ }^{1}$ College of Coastal Agricultural Sciences, Guangdong Ocean University, Zhanjiang 524088, P.R. China \\ ${ }^{2}$ College of Food Science and Technology, Guangdong Ocean University, Zhanjiang 524088, P.R. China \\ ${ }^{3}$ College of Chemistry and Environment, Guangdong Ocean University, Zhanjiang 524088, P.R. China \\ *Corresponding author. Email: liuying85168@126.com; yingbinxue@yeah.net
}

\begin{abstract}
In the field of higher education teaching, the development of virtual reality teaching is one of the important manifestations of education and teaching informatization, and its specific application has been increasingly extensive implemented. Based on the characteristics of virtual reality technology and the current situation of precision agriculture technology curriculum, the teaching method of precision agriculture technology after the integration of virtual reality was explored in this paper. Finally, a teaching model for precision agriculture technology based on virtual reality was established, providing an effective way to improve the teaching effect of precision agriculture technology.
\end{abstract}

Keywords: Teaching reform, Precision agriculture technology, Virtual reality.

\section{INTRODUCTION}

The course of precision agriculture technology mainly introduces the history, current situation and development trend of precision agriculture, and systematically expounds precision agriculture and its supporting technology-3S (GPS, RS, GIS), information monitoring, variable control and other technologies.

Virtual Reality (VR) technology is characterized by immersion, multi-perception, autonomy and interaction, and has been widely applied in many fields (Li, 2019; Tang, 2020). In the field of education, virtual reality technology can make two-dimensional knowledge and pictures into three-dimensional, build the teaching mode of self-perception, improve the rigid education mode, strengthen the means of practical education, and greatly improve the teaching quality. Based on the characteristics of virtual reality and the current teaching situation of precision agriculture technology, this project explored the teaching method of precision agriculture technology after the integration of virtual reality. We hoped to establish a teaching model of precision agriculture technology based on virtual reality, which would provide an effective way to improve the teaching effect of precision agriculture technology.
However, there were some problems in teaching of precision agriculture technology as follows.

\subsection{The Content of Practice Teaching Was Limited, and Some Practice Took A Long Time}

Precision agriculture technology was rich in content, but only some basic operation methods and skills could be learned in the limited class hours, which would hinder students to broaden their horizon and enrich their professional knowledge. In addition, due to the limitation of site and time, some traditional experiments were not conducive for students to master the practical operation skills of precision agriculture technology.

\subsection{The Teaching Hours of Precision} Agriculture Technology Were Reduced and the Participates Degree of Students Was Not High

With the deepening of curriculum reform in colleges and universities, the class hours of many courses had been compressed. The teaching hours of precision agriculture technology were less, which could not meet the teaching requirements of precision agriculture technology. In addition, in practice teaching, the teacher 
was the main, with the help of PPT to describe the operation steps, operation standards, and then do operation demonstration, while students could only imitate and verify the experimental results. This teaching method neglected students' dominant position in learning, which leaded to low enthusiasm and participation in the practice.

\subsection{The Teaching Method Was Very Monotonous, and Too Much Flipped Classroom Increased Students' Burden}

The greater openness of teaching made the characteristics of college education significantly different from that of middle school education. Moreover, most teachers had got rid of the fixed teaching methods -- classroom teaching and student group work, and wanted to make innovations in teacher mode, such as flipped classroom and group work. But in fact, this so-called "innovative" teaching method in today's college education had been difficult to arouse students' interests in learning. This more performancefocused teaching method was more likely to neglect students' ability training (Zou et al., 2020).

\subsection{The Student's Result Examination Method Was Relatively Unitary, Only Has the Effect of Talk about Stratagems on Paper}

In the long run, course assessment is often a motivation to correct students' learning attitude. At present, the result assessment and written examination of precision agriculture technology classroom accounted for a large part of the final marks, and the final examination became the only means to measure the learning level of the course. This kind of guidance would make many students only grasp the content on paper and memorize it for high scores without understanding the meaning. Therefore, students would lack the process of comprehensive analysis, independent thinking and adapting to local conditions in precision agriculture technology.

Therefore, the teaching methods and contents of precision agriculture technology needed to be further optimized and reformed. How to make full use of the existing technical means to seize students' interests and cultivate students' ability of independent analysis and thinking had become one of the difficult problems to improve the teaching effect of precision agriculture technology.

\section{THE PRACTICE OF VIRTUAL REALITY IN TEACHING OF PRECISION AGRICULTURE TECHNOLOGY}

Based on computer software and hardware, virtual reality is created by using a variety of technical means; it is a simulation of the known or unknown world ( $\mathrm{Li}$, 2019). Users can interact with the virtual world naturally with the help of a variety of sensing channels such as sensory organs; its interactivity and verisimilitude create a $3 \mathrm{D}$ virtual world that reflects the changes and interactions of physical objects in real time (Liu et al., 2020). Virtual reality might create various forms of teaching scenes for students to complete various types of practice, so as to optimize the teaching environment, enrich the teaching content and improve the teaching quality. Therefore, we wanted to introduce virtual reality into the teaching of precision agriculture technology course in order to improve the teaching effect.

\subsection{Construction of Virtual Reality Platform}

Decorating the existing classrooms, we should purchase large-screen monitors and head-mounted VR devices; and we should design appropriate scenes, actions and special effects, so that students could have interactive experience and expand information exchange with the virtual world. To develop the precision agriculture technology course in the form of "pass through" activities, students could be completely immersed in the virtual environment, using the virtual platform to adjust instruments and equipment by themselves, and completing each level according to the process prompts. During this period, students could get free energy and materials to continue learning. Therefore, students needed to complete tasks to obtain energy or materials, such as daily check-in, one-minute browsing of science popularization and interesting knowledge answering questions related to precision agriculture technology. Students could design and learn the operation methods of precision agriculture technology independently and complete the operation steps. students' interest in learning would be enhanced in a vivid way by VR.

\subsection{Construction of Shared Resource Library between Teachers and Students}

Teachers and students should build and share knowledge, experimental courseware, and information database of typical cases of precision agriculture technology practice firstly. Secondly, teachers and students could enter the resource database web terminal to share ideas, express opinions, raise questions, and so on, to facilitate the communication and discussion at anytime and anywhere, which promoted the play of students' subjective initiative. Thirdly, in order to meet the requirement of modern teaching, the course of precision agriculture technology should be given prominence to be student-oriented in terms of target setting, teaching process, curriculum evaluation and development of teaching resources, etc. What's more, 
teachers should give appropriate guidance direction to students.

\subsection{Expanding the Content of Practical Teaching}

When virtual reality was introduced into practical teaching of precision agriculture technology, the limitation factors of traditional teaching were broken, and a virtual reality practice platform with all aspects could be established. Precision agriculture technology course would be included different types of practices, such as the basic principles and applications of global positioning system, geographic information system and remote sensing, etc. Different virtual reality practice platforms were designed according to various experimental characteristics to cultivate innovative and applied biological talents.

\subsection{Reforming the Assessment System and Paying Attention to the Investigation of Comprehensive Ability}

According to the course characteristics of precision agriculture technology, attentions should be paid to the combination of practice and theory, and the assessment of students' experimental skills. The virtual reality platform also added in doing exercises and exams. Through real-time collection of students' completion time and accuracy rate of doing exercises, the big data of education could be formed to quickly find students' problems and bottlenecks in learning. In traditional experimental operation, it was impossible for teachers to pay timely attention to each student's mastery of experimental operation in a timely manner, and the assessment only was measured experimental skills through the writing of experimental reports. However, in the experimental virtual reality platform, the system could automatically monitor the experimental operation process of students, and evaluate and score them, breaking through the shortcomings of traditional experimental assessment, instead of only paying attention to the mastery of theoretical knowledge. This kind of assessment system could not only realize teachers' assessment of students' experimental operation skills, but also realize students' self-assessment.

\section{CONCLUSIONS}

Virtual reality is a simulation of the known or unknown world based on computer software and hardware. Users can interact with the virtual world naturally with the help of various sensing channels such as sensory organs. Its interactivity and fidelity create a three-dimensional virtual world reflecting the changes and interactions of physical objects in real time for users (Liu et al., 2020; Zhai et al., 2020). Virtual reality can create various forms of practical operation teaching scenes for students to complete various types of precision agriculture technology, so as to optimize the practical teaching environment, enrich the practical teaching content, and improve the quality of experimental teaching.

With the rapid development of computer networks, the information construction of higher education technology is becoming more and more advanced and perfect (Liu et al., 2020). Precision agriculture technology in our school teaching is conformed to the trend of the development of the informatization practical education. With the help of the virtual reality technology, we want to create a highly realistic virtual laboratory. To a large extent, it supplements and realizes the teaching function that traditional laboratory cannot accomplish, enriching the content of experiment teaching, and improving the teaching quality of precision agriculture technology. With the assistance of virtual reality, professional talents of innovative agricultural will be cultivated, which adapted to the demand of the development of modern society and agricultural industry.

\section{AUTHORS' CONTRIBUTIONS}

Ying Liu and Yingbin Xue conceived and designed the experiments. Ying Liu, Gangshun Rao, Jianping Chen, Hanqiao $\mathrm{Hu}$, Yuduan Ou and Yingbin Xue collected information. Ying Liu analyzed the information. Ying Liu and Yingbin Xue wrote the manuscript. All authors have read and approved the final manuscript.

\section{ACKNOWLEDGMENTS}

This work were supported by Natural Science Foundation of Guangdong Province (2018A030310057 and 2020A1515011570), Program for Nanhai Youth Scholar Project of Guangdong Ocean University (002029001012), Program for Scientific Research Startup Funds of Guangdong Ocean University (R17023 and R19031), the Project of Science and Technology of Zhanjiang City (2016B01004 and 2020B01019), the Project for Innovation and Strong School of Department of Education of Guangdong Province (2019KTSCX059), Education Teaching Reform Project of Guangdong Ocean University (524210393), Teaching Project of Innovation and Strong School Engineering of Guangdong Ocean University (524210441), Postgraduate Education Innovation Program of Guangdong Ocean University (521002098), and the Industry-University Cooperative Education Project of the Ministry of Education of China (201902119004).

\section{REFERENCES}

[1] L. Li, Necessity, existing problems and sustainable development mechanism of virtual simulation 
experiment teaching. Journal of Hubei Open Vocational College, 2019,7: 151-153.

[2] R. Liu, X.Y. Jiao, Y. Liu, et al., Application of virtual simulation technology in the pharmaceutical experiment teaching of traditional Chinese medicine. Education Teaching Forum, 2020, 27: 389-390.

[3] B. Tang, Teaching reform and practice of product design course under the background of virtual simulation technology. Education Garden, 2020, 6: 193-194.

[4] K.F. Zhai, H. Duan, W.G. Cao, et al., Reform and practice of bio-pharmaceutical training course based on virtual simulation technology. Journal of Jilin Medical University, 2020, 3: 235-236.

[5] Q.L. Zou, T.C. Zhang, Y. Liu, et al., Teaching reform approach of safety evaluation based on virtual simulation technology. Journal of Higher Education, 2020, 29: 114-117. 